large null-cell group. Even within this group, however, survival varies widely, and other presenting features may also be of value in assessing prognosis. The most reliable of these are the leucocyte (or blast-cell) count and the degree of clinical enlargement of liver, spleen, and lymph nodes-all indicators of the total body burden of leukaemic cells at diagnosis, which in turn probably reflects the proliferative rate of the malignant clone. In general, the longest remissions and survivals tend to be achieved in those patients with the lowest leucocyte counts and with minimal organ enlargement. ${ }^{23}$ Age and racial origin also have prognostic significance: children aged less than 2 years or over about 10 do less well than those between these ages, ${ }^{45}$ and Black children less well than White. ${ }^{6}$ Other adverse prognostic features include mediastinal involvement - usually a sign of T-cell leukaemia-and early evidence of spread to the central nervous system.

Claims have also been made for the prognostic value of subclassification of leukaemic lymphoblasts on grounds of size $^{7}$ or more subjective morphological criteria, ${ }^{8}$ but these have been strongly disputed. ${ }^{9-11}$ Among cytochemical methods, the acid phosphatase positivity of lymphoblasts correlates well with their $\mathrm{T}$-cell nature ${ }^{12}$ and has a corresponding prognostic significance. But the degree of periodic acid Schiff (PAS) positivity, which has been claimed to be positively correlated with duration of remission, is at best only a weak indicator of prognosis.

Many of these prognostic features are interrelated, so that it is difficult to decide how much reliance to place on each or to what extent the apparent effect of one feature may depend on its frequent association with another. As Tsukimoto et al ${ }^{13}$ have suggested, for example, the adverse effect of a high leucocyte count, negative PAS reaction, and early spread to the central nervous system may be partly attributable (like that of mediastinal lesions) to their frequent association with $\mathrm{T}$-cell leukaemia. The poorer response of older children-and of boys than girls in some reported series-may also be partly attributable to the same cause, since this type of ALL is much more common in boys and has a somewhat older age incidence than the null-cell variety.

The influence of these various features clearly differs from one treatment regimen to another, ${ }^{14-16}$ and the careful analysis of such interactions between prognostic features and treatment may help us to devise more effective regimens for particular classes of patient. We can recognise a group of patients with null-cell ALL, aged between 2 and 10 years, with leucocyte counts below $20000 \mu l$ and only minor degrees of enlargement of liver, spleen, or lymph nodes, who have, perhaps, a greater than $60 \%$ chance of continuous complete remission for four years or more on any of several current therapeutic regimens, with the probability that a substantial proportion will prove to be cured. What of the others ? Should they be treated more intensively, or do they require a radically different approach ? Therapeutic trials designed to answer these questions are currently being carried out by several collaborative groups, including the Medical Research Council's Working Party on Leukaemia in Childhood. In the good prognostic group the present encouraging position has been reached by means of cranial radiotherapy and moderately intensive combination chemotherapy at the cost of a proportion of deaths from opportunistic infections during remission of the leukaemia. Such deaths are now of the same order of frequency as those from the leukaemia itself, ${ }^{17}$ and in this group of patients greater improvement may be expected from modifying treatment regimens so as to reduce their immunosuppressive and myelotoxic effects than from further intensifying them.
1 British Medical fournal, 1975, 1, 111

Till, M M, Hardisty, R M, and Pike, M C, Lancet, 1973, 1, 534.

${ }^{3}$ Simone, J V, Advances in the Biosciences, 1975, 14, 27.

${ }^{4}$ Medical Research Council, British Medical fournal, 1971, 4, 7.

5 Cangir, A, George, S, and Sullivan, M, Cancer, 1975, 36, 1973.

${ }^{6}$ Walters, T, Bushore, M, and Simone, J, Cancer, 1972, 29, 210.

Pantazopoulos, N, and Sinks, L F, British fournal of Haematology, 1974, 27, 25.

${ }^{8}$ Mathé, G, et al, European fournal of Clinical and Biological Research, 1971, 16, 554.

${ }^{9}$ Bernard, J, et al, Advances in the Biosciences, 1975, 14, 97.

${ }_{10}$ Murphy, S B, et al, British fournal of Haematology, 1975, 31, 95

11 Oster, M W, et al, British fournal of Haematology, 1976, 33, 131.

12 Catovsky, D, et al, fournal of Clinical Pathology, 1974, 27, 767.

13 Tsukimoto, I, Wong, K Y, and Lampkin, B C, New England fournal of Medicine, 1976, 294, 245.

${ }^{14}$ Medical Research Council, British Medical fournal, 1971, 4, 189.

${ }_{15}$ Medical Research Council, British Medical fournal, 1973, 2, 381.

${ }^{16}$ Hardisty, R M, Kay, H E M, and Smith, P G, in Therapy of Acute Leukaemias, eds F Mandelli et al, p 97. Rome, Minerva Medica, 1975.

17 Medical Research Council, British Fournal of Haematology, 1976, 33, 179.

\section{Bronchodilators, new and old}

Obstruction of the airways in asthma and chronic bronchitis may partly be caused by sputum or mucosal thickening, but it is the spasm of bronchial smooth muscle which we generally treat with one or more of the many bronchodilator preparations. ${ }^{1}$ During acute attacks of asthma or exacerbations of chronic bronchitis we aim to reverse established bronchospasm and often use corticosteroids, oxygen, and other therapeutic measures in addition to bronchodilators. When treating a patient with chronic airway obstruction we hope to prevent or minimise the development of bronchospasm.

The last decade has seen advances in the delivery of aerosols and in the development of newer and more specific drugs. In many instances the choice of the correct route of administration is as important as the choice of drug. Of the drugs available, the sympathomimetics are the most familiar. Adrenaline and ephedrine have been used for many years but have the disadvantage of stimulating $\alpha$-adrenoceptors (which causes vasoconstriction with a rise in blood pressure and might even cause bronchoconstriction) as well as $\beta$-adrenoceptors (which leads to bronchodilatation, vasodilatation, and tachycardia). Isoprenaline predominantly stimulates the $\beta$-adrenoceptors, but it is unselective: it stimulates both the $\beta_{2}$-adrenoceptors of the bronchial smooth muscle to produce bronchodilatation and the $\beta_{1}$-adrenoceptors of the heart, increasing its forcefulness and rate of contraction. The cardiac stimulant effects of isoprenaline may be minimised if the patient inhales small amounts directly into the lungs, and tachycardia is not seen in asthmatic patients who use recommended doses from metered dose inhalers. ${ }^{2}$ Inhaled isoprenaline produces maximal bronchodilatation within a few minutes, but its effects wear off within one to two hours. ${ }^{3}$

Several selective $\beta_{2}$-adrenoceptor stimulants have been developed, but they may still cause tachycardia in large doses, possibly secondary to $\beta_{2}$-induced vasodilatation, and they have other side effects such as tremor. Rimiterol has a time course of action rather similar to isoprenaline, ${ }^{4}$ and orciprenaline, ${ }^{5}$ isoetharine, ${ }^{6}$ salbutamol, ${ }^{7}$ and terbutaline ${ }^{8}$ are longer acting. There is probably little to choose among these drugs in clinical practice, ${ }^{910}$ though most physicians and patients have their own favourites. 
In acute attacks of asthma administration of bronchodilators is an important part of treatment. Nevertheless, the use of metered dose inhalers will probably be ineffective if the patient has severe airway narrowing. A wet aerosol of one of the $\beta_{2}$-selective stimulants produced by a nebuliser or in association with an intermittent positive pressure ventilator is probably the best way of producing the greatest effect with the lowest dose and the least risk of side effects. ${ }^{11}$ If parenteral treatment is indicated then subcutaneous terbutaline ${ }^{12}$ and intravenous salbutamol $^{13}$ are effective. In theory, all of these agents may adversely affect ventilation-perfusion relationships and make hypoxia worse, but severely ill patients in whom this would be clinically important should be receiving controlled oxygen treatment. ${ }^{14}$ The longer-acting selective $\beta_{2}$-adrenoceptor stimulants are also useful for maintenance treatment, though it is advisable to confirm that they do produce a worthwhile improvement in lung function tests before starting such treatment. Again, aerosols are preferable, and metered-dose inhalers are convenient and safe provided the patient is warned to seek medical advice if his inhaler does not bring relief when used according to instructions. Some patients cannot synchronise inhalation with aerosol activation, or may develop inspiratory flow rates that are too low for adequate delivery of the drug; in these cases oral preparations should be used.

Stimulation of the $\beta$-adrenoceptors increases the activity of adenyl cyclase and this promotes the formation of cyclic AMP within the cell and results in bronchodilatation. ${ }^{15}$ Theophylline and its derivatives prevent the breakdown of cyclic AMP by inhibiting phosphodiesterase, and in adequate doses they can be effective bronchodilators, ${ }^{16}$ though some preparations irritate the stomach. Theophylline and sympathomimetics in combination have additive effects, ${ }^{17}$ and tablets containing theophylline, ephedrine, and a barbiturate are often popular with patients. When prescribing these preparations, however, the doctor must remember that ephedrine may precipitate urinary retention in elderly men and that barbiturates may depress the respiratory centre or increase corticosteroid requirements by inducing hepatic enzymes. Rectal aminophylline is widely used, but the hazards of rapid intravenous injection of aminophylline or uncontrolled infusion for over $24 \mathrm{hrs}$ are now well recognised. ${ }^{18}$

Some patients may become resistant to sympathomimetics, ${ }^{19}$ and this might be one reason for using the least popular group of bronchodilators, the parasympatholytics. Atropine and its derivatives have been widely used for centuries to relieve asthma, and a recent symposium has reviewed the place of these drugs in current treatment. ${ }^{20}$ The role of the parasympathetic nervous system in the regulation of airway calibre has been shown in animals, ${ }^{21}$ and atropine can prevent the responses of asthmatic patients to inhaled irritants ${ }^{22}$ or even allergens. ${ }^{23}$ Atropine is generally as effective a bronchodilator as isoprenaline, though its effects take longer to develop and last longer. ${ }^{3}$ This made the combination of atropine and isoprenaline in aerosols rational before the development of the longer acting sympathomimetics. As with other bronchodilators, potential side effects (such as urinary retention and failure of accommodation) may be avoided by the use of aerosols. The theoretical risk of drying bronchial secretions and blocking airways with viscid sputum does not seem to be a problem in practice. ${ }^{24}$ In fact, studies of both atropine ${ }^{25}$ and an analogue of atropine, ipratropium bromide, ${ }^{26}$ have suggested that parasympatholytics may be more effective in patients with chronic bronchitis than in patients with asthma. Further longterm studies are needed, but this type of drug may be of particular use for patients with chronic airway obstruction who are already receiving maximal doses of sympathomimetics, or in those who find their side effects troublesome.

${ }^{1}$ Paterson, J W, and Sheffield, G M, BTTA Review (Tubercle), 1974, 4, 25 and 61.

${ }^{2}$ Paterson, J W, et al, Lancet, 1968, 2, 426.

3 Chamberlain, D A, Muir, D C F, and Kennedy, K P, Lancet, 1962, 2, 1019.

Marlin, G E, and Turner, P, British Fournal of Clinical Pharmacology, 1975, 2, 41.

5 Engelhardt, A von, et al, Arzneimittel-Forschung, 1961, 11, 521.

6 Lands, A M, et al, Nature, 1967, 214, 597.

7 Cullum, V A, et al, British fournal of Pharmacology, 1969, 35, 141.

${ }^{8}$ Persson, H, and Olsson, T, Acta Medica Scandinavica, 1970, Suppl 512, 11.

${ }^{9}$ Drug and Therapeutics Bulletin, 1972, 10, 7.

${ }_{10}$ Drug and Therapeutics Bulletin, 1973, 11, 39.

11 Choo-Kang, Y F J, Parker, S S, and Grant, I W B, British Medical Fournal, 1970, 4, 465.

12 Arner, B, et al, Acta Medica Scandinavica, 1970, suppl 512, 41.

${ }^{13}$ Fitchett, D H, McNichol, M W, and Riordan, J F, British Medical fournal, 1975, 1, 53.

14 British Medical fournal, 1976, 1, 609.

${ }^{15}$ Robinson, G A, Butcher, R W, and Sutherland, E W, Annals of the New York Academy of Sciences, 1967, 139, 703.

${ }^{16}$ Piafsky, K M, and Ogilvie, R I, New England fournal of Medicine, 1975, 292, 1218.

17 Cander, L, and Comroe, J H, fournal of Allergy, 1955, 26, 210.

18 Lancet, 1973, 2, 950.

19 Paterson, J W, Evans, R J C, and Prime, F J, British fournal of Diseases of the Chest, 1971, 65, 21.

${ }^{20}$ Postgraduate Medical fournal, 1975, suppl 51, 7.

21 Cabezas, G A, Graf, P D, and Nadel, J A, fournal of Applied Physiology, $1971, \mathbf{3 1}, 651$.

22 Simonsson, B G, Jacobs, F M, and Nadel, J A, fournal of Clinical Investigation, 1967, 46, 1812.

${ }^{23}$ Yu, D Y C, Galant, S P, and Gold, W M, fournal of Applied Physiology, $1972,32,823$.

${ }^{24}$ Lopez-Vidriero, M T, et al, Thorax, 1975, 30, 543.

25 Alliott, R J, et al, British Medical fournal, 1972, 1, 539.

${ }^{26}$ Petrie, G R, and Palmer, K N V, British Medical fournal, 1975, 1, 430.

\section{Student loans}

With the announcement of yet another round-of public expenditure cuts, yesterday's inconceivable solution for saving money becomes tomorrow's candidate for discussion. There seems a strong argument, therefore, for taking out of the drawer-and re-examining-the case for introducing some system of student loans ${ }^{1}$ to relieve the financial pressure on the higher education system. The Government's new and much higher scale of university fees appears to be designed primarily to make foreign students pay a higher proportion of the costs of their education, but it would be optimistic to assume that this will be the last attempt to economise on higher education. Moreover, since medical education is inescapably and unavoidably one of the most expensive forms of training, it may well attract the attention of the Treasury hatchet-men.

The higher education sector is already under considerable pressure. The spending plans announced by the Government in February were based on the assumption that the student numbers would increase faster than expenditure levels. As the Expenditure White Paper ${ }^{2}$ put it, somewhat euphemistically, "The planned level of current expenditure will require a progressively more effective use of resources." In other words, spending per head is intended to fall. ${ }^{3}$ So any further cuts in the higher education budget would almost certainly mean lower standards.

In this new context, many of the old doubts about student loans are not as persuasive as they used to be. If a system of loans were to permit students to pay more towards the cost of their own education-and if, consequently, the higher education sector were to be at least partly emancipated 